\title{
Competitive horizons
}

Germany to impose tough recycling targets on firms

\section{China's increased production of electric cars will see demand for base metals soar}

\section{How website content can persuade browsers to spend}

\section{E-commerce seen as valuable opportunity for Zimbabwean firms}

In early 2019, new packaging regulations will come into force for companies doing business in the German market. Firms will have to meet strict recycling quotas or face penalties that can reach €50,000. Trading bans can also be handed out, a report published by www. plasticsnewseurope.com notes. Upward revision means that recycling of plastics must rise from the present 36 to 63 per cent by 2022. Over the same period, a 90 per cent target for metal, glass and paper recycling has been set. Expectations for reusable packaging have likewise been significantly increased. A goal of 70 per cent for reusable drinks packaging is one example of this. The report further points out that all companies operating in the market must also enroll on the central packaging register, while firms that produce certain volumes of packaging are compelled to sign a declaration of compliance (DOC). Large fines are possible for firms that fail to meet this obligation. All businesses are governed by this new legislation, whether they manufacture, import, distribute or sell goods online.

Manufacturers of base metals such as copper, nickel, lithium, cobalt and ferrochrome are set to benefit as China strengthens its position as the world's biggest market for electric vehicles (EVs). Demand for the metals has already increased as the market has grown and industry insiders predict that the trend will continue strongly as EVs start to be mass produced. A report published by www.china.org comments on the optimism about the growing use of cobalt and belief that copper producers will gain substantially. Relative to conventional medium-sized cars, their emerging electric counterparts include around four times as much of the metal. The report reveals China's aim to raise production and sales of EVs to 2 million by the end of the current decade. And the expectation is that 2030 will see this figure rise to 15 million.

An article published by www.startups.co.uk contends that a few tweaks can help embryonic businesses convert website visitors into buyers. Content is key and it's important to show potential customers ways in which the firm's products can benefit them. For instance, the emphasis might be on cost, ease-of-use or even pleasure. Creating a blog on the site is a proven idea but will only succeed if the language, style and tone adopted are appropriate to the target audience. It is equally imperative to make sure the topics covered are relevant and of interest to them. Trust cannot be underestimated and one sure way of gaining this from site visitors is to include positive reviews and testimonials from other customers. Evidence suggests that over half of potential buyers can be swayed by such content. Finally, the article advocates creating a sense of urgency among browsers. This can be achieved through shrewdly-placed site messages informing them that supplies of certain products are selling out fast or on limited availability. This often prompts many people to act quickly as they fear missing out on a specific deal.

A strong focus on e-commerce can help micro, small and medium-sized companies in Zimbabwe to flourish, a report produced by ZimTrade claims. According to the nation's export promotion body, increasing internet availability enables such operators to capture a share of online trade and access global markets. The report, as published by www. thestandard.co.zW, encourages firms to invest in order to strengthen their online presence and become better positioned to add value to customer offerings. It will also help them to exploit emerging technologies and market trends. Companies are also urged to make use of the various social media platforms available to them. Increasing their activity on channels like Facebook, Instagram and Pinterest enables them to achieve sales and marketing goals and overall export growth. However, ZimTrade does acknowledge that issues that can include internet instability and inadequate support systems do make e-commerce challenging at times. 